\title{
Measuring online consumer behavior: scale development \& validation
}

\author{
Zaid Ahmad Ansari \\ Department of Business Administration \\ College of Business and Economics, Qassim University, Saudi Arabia
}

\section{Keywords}

E-commerce, Online Consumer Behavior, Scale Development, Web atmosphere

\begin{abstract}
The purpose of this paper is to measure online consumer behavior in Saudi Arabian context. The study has identified 7 factors like Web Atmosphere, E-Retailors Image, attitude, Trust, Situational factors, social factors and cultural factors which have a significant influence on the online consumer behavior. These seven factors have been measured using 35 statements. The scale developed has shown strong internal consistency, reliability and has remained consistent across different samples. The findings have revealed that web atmosphere is one of the most dominant factors along with the E-Retailors image and cultural factor have emerged out to be least significant factor. The main contribution of this study lies in validating a divergent scale measuring online consumer behavior. The findings of this study have important implications both for the academia and practitioners. The limitations and directions for future research are also discussed.
\end{abstract}

Corresponding author: Zaid Ahmad Ansari

Email address for corresponding author: drzaidansari@gmail.com

First submission received: $1^{\text {st }}$ May 2018

Revised submission received: $5^{\text {th }}$ July 2018

Accepted: $12^{\text {th }}$ August 2018

\section{Introduction}

Saudi Arabia is a country which is unusual in every possible way imaginable. A country where majority of the people like to go out for shopping in humongous and giant air-conditioned malls. People like to pay in cash and therefore postal codes are hardly used. This makes building online retail business presence much more difficult and complicated than any other country in the world. With the entry of American E-commerce giant, 'Amazon' and local players like 'Souq' and 'Noon.com' things are expected to take a U-turn pretty soon because E-commerce gives information and communication not only to businesses but to consumers as well (Maghrabi \& Dennis, 2011). According to the recent data from Reuters the online sales in Saudi Arabia is expected to surge to $\$ 13.9$ billion by 2021 from $\$ 8.7$ billion in 2017.

The research on E-commerce has seen quite a surge over the last decade. The research on online consumer behavior has appeared in some of the prominent journals of management, marketing, information technology and even phycology. A close introspection of the previous research which has appeared in these journals highlights that researchers have drawn theories from classical consumer behavior research like behavioral learning (skinner,1938), personality research (Folkes, 1988), information processing (Bettman, 1979) and attitude models (Fishbein, 1975). Although, I acknowledge that the application is not that straightforward as simply borrowing the theories because significant differences exist between online and offline behaviors of the consumers.

Despite the surge in academic and non-academic literature in studying online consumer behavior, there is still dearth of studies which have attempted to integrate research findings across studies from a theoretical marketing and consumer behavior perspective (Darley \& Blankson, 2010). Further very rare papers have studied the online consumer behavior with respect to Saudi Arabia. Therefore, there is a need to bride this gap by constructing a valid measuring instrument which will help online businesses 
understand the major factors which have an influence on the overall consumer behavior. Despite encouraging and high online growth rates researchers argue that many customers who search products on multiple online sites abandon their purchase decisions Talal Al et al., (2010). This is critical because previous research has highlighted that acquiring new customers may be five times costlier than acquiring an old one (Bhattacherjee, 2001; Crego \& Schiffrin, 1995; Petrissans, 1999).

Therefore, the objective of this paper is to construct, test and validate a scale for measuring online consumer behavior in E-commerce with special emphasis on the Saudi Arabia. Researchers have considered E-commerce as a reference point because there is a paucity of studies in the available literature. Researcher has tried to bridge this gap by constructing a highly valid and reliable scale which measures the consumer behavior in E-commerce. The rest of the paper is organized into 5 main sections. First, a thorough review of literature has been conducted highlighting all the previous measures of ecommerce. Second, highly valid and reliable scale development procedures as per the recommendations of Churchill (1979) and Hinkin (1995) have been discussed. Third, the researcher has discussed the implications of the study along with the limitations and directions for future research.

\section{Review of literature}

Escalation in internet usage pushed the commerce into digital age, affecting almost every aspect of day to day life, from knowledge to acquisition of the products and services (Kim \& Lennon, 2008). Recently internet prevalence intensified the study of consumer based electronic commerce (Cheung, Chan, \& Limayem, 2005). The significant growth in the literature of online consumer behavior is highly acknowledged over the last decade (Darley, Blankson, \& Luethge, 2010) and consequently it has become an emerging area of research (Cheung et al., 2005).

According to Cheung at al. (2005) online consumer behavior became one of the emerging areas of research since 2000, due to dramatic increase in the number of publications per year. The literature reveals that, most of the discussion related to consumer behavior confines to its factors or components. Researchers have different opinions when defining the components of the consumer behavior. The literature also revealed that consumer behavior is measured through diverse factors. One of the major and most important component discussed in the literature is related to web atmosphere which includes a number of web specific aspects like, experience with internet and internet self-efficacy (Aljukhadar \& Senecal 2011); online risk (Bianchi \& Andrews 2012); online technology enjoyment, familiarity with online transactions, and online purchase intension (Chen \& Barnes 2007); navigation (Childers, Carr, Peck, \& Carson, 2001); screen clarity, content relevance, and link relevance (Demangeot \& Broderick 2007); characteristics and evaluation of websites (Kim, Yang, \& Yong Kim, 2013); Navigation (Liang \& Lai 2002); web experience and site quality (McKnight, Choudhury, \& Kacmar, 2002); interface (Schoenbachler \& Gordon 2002) are frequently studied in consumer behavior studies.

Second widely discussed component or factor of consumer behavior is e-retailers image which covers company size and reputation (Chen \& Barnes 2007); retailer image and reputation (Constantinides, 2004; Dennis, Merrilees, Jayawardhena, \& Tiu Wright, 2009; Eurofood, 2000); retailer reputation (Kim, Yang, and Yong Kim, 2013; Korgaonkar, Silverblatt, \& Girard, 2006). Highlighting the importance image in e-commerce Boulding (1956) reported "image" signifies comprehensive evaluation or rating of something in such a way that guide the actions of consumers. Similarly, Constantinides, (2004) suggested that retailer image and reputation help in reduction of customer anxiety by lowering transaction risks and by enhances virtual interactions.

Third important component discussed in the literature of consumer behavior is consumer's attitude (Bhattacherjee, 2000; Bianchi \& Andrews 2012; Chan, Cheung, Kwong, Limayem, \& Zhu, 2003; Childers, Carr, Peck, \& Carson, 2001; Goldsmith \& Bridges 2000; Hansen 2008; Kang, Hahn, Fortin, Hyun, \& Eom, 2006; Koernig, 2003; Lim, \& Dubinsky, 2005; Menon, \& Kahn, 2002; Schiffman, Sherman, \& Long, 2003; Shim, Eastlick, Lotz, \& Warrington, 2001; Song, \& Zahedi, 2005; Sorce, Perotti, \& Widrick, 2005)

Fourth subsequent factor of consumer behavior is trust which includes disposition to trust, institution-based trust, trusting beliefs, and trusting intentions (McKnight, Choudhury, \& Kacmar, 2002), propensity to trust (Bianchi \& Andrews 2012; Aljukhadar \& Senecal 2011; Chen \& Barnes 2007; Cheung, \& 
Lee, 2001; Fung, \& Lee, 1999), benevolence trust (Cho, 2006), interpersonal trust (Das, Echambadi, McCardle, \& Luckett, 2003), trust (Dash, \& Saji, 2008; Falk, Schepers, Hammerschmidt, \& Bauer, 2007; Jarvenpaa, Tractinsky, \& Vitale, 2000; Lee, \& Turban, 2001; Jiang, Jones, \& Javie, 2008; Lee, Kim, \& Moon, 2000).

One of the other widely discussed components include situational factors of e-consumer (Darley, Blankson, \& Luethge, 2010; Dennis et al., 2009; Rohm \& Swaminathan 2004). Various researchers' e.g Evanschitzky, Iyer, Hesse, \& Ahlert, (2004); Szymanski, \& Hise, (2000), argue that perception of convenience acts as one of the important situational component in online shopping, and also significantly influences e-satisfaction of consumers (Kim, Kim, \& Kandampully, 2009), in this issue Dennis et al. (2009) suggested convenience in online shopping eliminates costs (travel and psychological) and enhances efficiency of e-consumers.

The next subsequent component highlighted in literature of consumer behavior is social factors (Ajzen \& Fishbein, 1980; Dennis et al., 2009; Darley, et al., 2010; Engel, Blackwell, \& Miniard, 2001; Lim, \& Dubinsky, 2005). In context of social factors, the theory of reasoned action (TRA) argues that even wishes of our best friends on purchase of particular items effects our intention (Dennis et al., 2009). Likewise, Rohm \& Swaminathan (2004) found that social influence of e-consumers acts as a significant motivator for online shopping. On similar lines Parson (2002) reported that social factors like outside experiences, communication with people of similar interest, peer group membership, and social status acts as valid motivators of online shopping.

Other main component widely discussed by researchers is cultural factors (Barnes, Bauer, Neumann, \& Huber, 2007; Bianchi \& Andrews 2012; Darley, et al., 2010; Davis, Wang, \& Lindridge, 2008; Engel, et al. 2001; Keen, Ruyter, Wetzels, \& Feinberg, 2000; Khan, Asad, \& Mehboob, 2017; Richard, \& Habibi, 2016; Shavitt, \& Cho, 2016). Highlighting its importance in online consumer behavior, researchers asserted culture has a significant influence on online interferences and e-consumers (Davis, et al., 2008; Mazaheri, Richard, \& Laroche, 2011). One of the most challenging tasks in marketing process is gaining and retaining of customers. In this context Kim (1999) proposed customer interface of a store should be designed in such a way that it attracts and retains the cross-cultural customers. Researchers suggested that the retention of the customers is only possible when a website of online stores reflects (Barber \& Bardrew 1998) and adapt atmospherics (Chau, Cole, Massey, \& O'Keefe 2002) of different cultural nuances. Supporting the notion Hofstede, Steenkamp, \& Wedel (1999) agree that cultural nuance is one of the essential stating while studying individual behaviors.

\section{Scale Development}

Present study adopts renowned scale development procedure proposed by Churchill (1979), which is augmented by various eminent researchers like, Anderson \& Gerbing (1982); Bagozzi, Youjae, \& Lyne, (1991); Nunnally \& Bernstein (1994) and Hinkin (1995). The scale development procedure (Bhat \& Bashir, 2017) is shown in Fig 1.

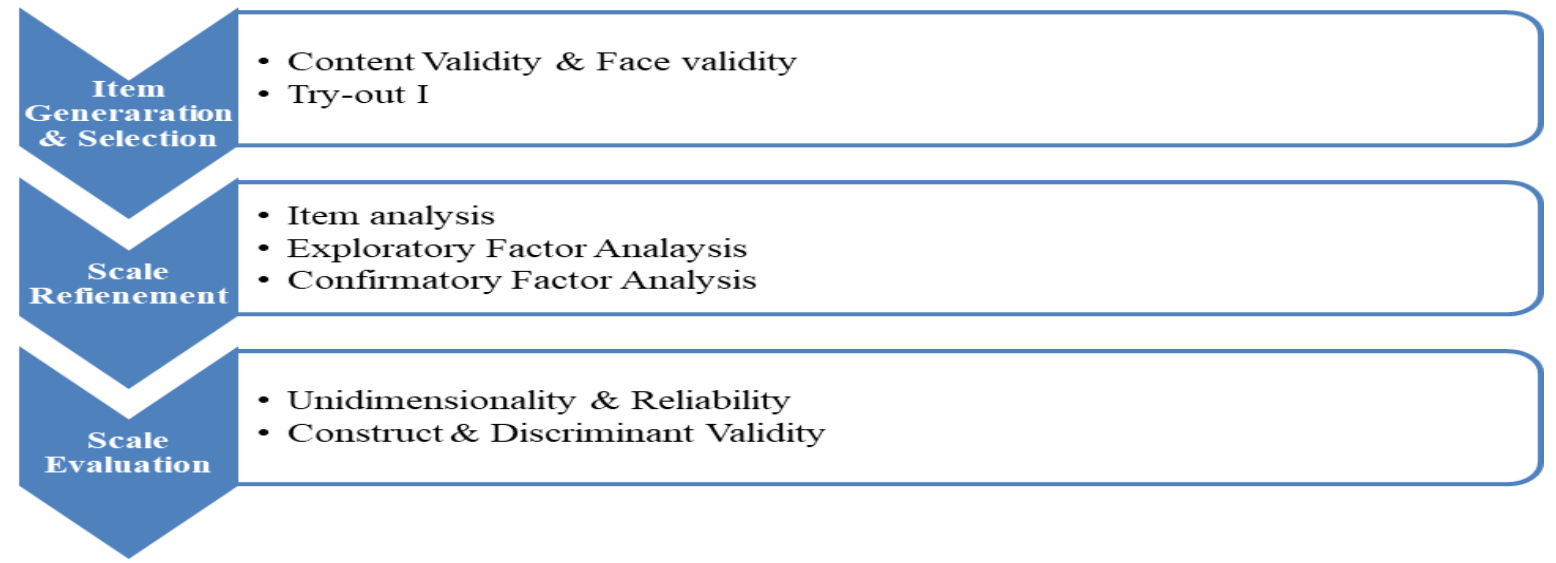

Fig. 1 Scale development procedure. Source: Bhat \& Bashir (2017). 


\section{Phase I: Item generation and selection}

Content Validity: In present study deductive method of scale development procedure has been adopted as per the suggestions of Hinkin (1995). To identify the proposed factors of consumer behavior in ecommerce sector an extensive review of literature dealing with various factors of consumer behavior was conducted. Getting insights from literature an initial set of 65 items was framed, each statement of consumer behavior is rated on a 5-point Likert scale with 5 as "strongly agree" and 1 as "strongly disagree".

After item generation, item pool was reviewed by a panel of 10 experts (Professors) on three categories, i.e. "clearly representative", "somewhat representative", and "not representative" (Lin \& Hsieh 2011). The result of close scrutiny lead to deletion of 6 overlapping items. After revision the scale was again send to panel of experts at several occasions which lead to elimination of 3 more items. In next stage evaluation of content validity was carried out by computing content validity ratio (CVR), CVR $=\frac{\mathrm{Ne}-\mathrm{N} / 2}{\mathrm{~N} / 2}$ as recommended by Lawshe (1975), (' $\mathrm{Ne}^{\prime}=$ no. of experts who favored the item and ' $\mathrm{N}$ ' is total no. of experts). The calculated CVR value ranged from 0.57 to 0.85 indication a good content validity.

(ii) Try-out I: To conduct the pilot testing of consumer behavior scale, draft consisting of 56 items evaluated on a five-point scale (where 1 strongly disagree and 5 strongly agree). The scale was divided into two sections, first part taps demographic information of respondents like; gender, age, qualification, locale, and second part contain 56 statements measuring consumer behavior. A sample of 300 respondents from residents of Saudi Arabia were collected for pilot testing of scale, which is in-line with Parsuraman, Zeithaml, \& Berry, (1988); Karatepe, Yavas, \& Babakus, (2005); Garg, Rahman, \& Qureshi, (2014); and Bhat \& Bashir (2017). The respondents of the present study were selected by employing convenience sampling technique, 650 questionnaires were distributed, after repeated reminders only 316 were returned. The collected questionnaires were carefully evaluated for missing information, outliers, and respondent disengagement (Hair et al. 2010). After data cleaning process 16 responses were discarded, the cleaned data set of 300 responses gives a response rate of $46.15 \%$. Out of 300 respondents approx. $80 \%$ of respondents were males and $20 \%$ were females, similarly $67 \%$ of sample belongs to age group of $20-40$ and $33 \%$ respondents belongs to age group of $41-70$. Likewise, $72 \%$ of respondents were urban and $28 \%$ belong to rural areas. Among 300 respondents $61 \%$ were graduates, $23 \%$ of respondents holds master's degree and $16 \%$ were having doctorate.

\section{Phase II: Scale refinement}

Item Analysis: Churchill (1979) recommended calculation of Cronbach a, as foundation stone of scale refinement. Researcher calculated Cronbach a for all the factors of consumer behavior with the help of SPSS 21, the value of alpha ranged from 0.690 to 0.790 , but the satisfactory value of a is 0.7 (Nunnally 1978). To improve the value of Cronbach's alpha researcher rechecked the item to tem correlations for each cluster of items. Items having low correlations were deleted after repeated iterative sequence, which resulted in deletion of 6 items. The improved value of alpha ranged from 0.763 to 0.815 .

Exploratory Factor Analysis: In refinement phase next step after item analysis is to explore exploratory factor analysis. Researchers conducted exploratory factor analysis on 50 remaining items using SPSS 21.0. EFA determine the state of instrument where there are unknown links between latent and observed variables. Researchers used principal component analysis along with varimax rotation to extract significant factors (Costello, \& Osborne, 2005). Items having factor loading $>.50$ (Karatepe, Yavas, \& Babakus, 2005) or communalities < .30 (Hair et al., 1998) were deleted. The value of Kaiser-Meyer-Olkin (KMO) statistics was 0.917 which higher than the value of 0.60 (Tabachnick \& Fidell, 1996) which determines the appropriateness of analysis. The EFA further revealed that online consumer behavior scale decomposed into 6 factors with Eigen values greater than 1 which explained $71.56 \%$ variance. During the EFA process 8 items were dropped as they did not qualify the minimum criteria mentioned above, finally 42 items covering 7 factors were retained refer to Table 1 . 


\begin{tabular}{|c|c|c|c|c|c|}
\hline Items & $\begin{array}{c}\text { Web Atmosphere E-Retailer } \\
\text { Image }\end{array}$ & Attitude & Trust & $\begin{array}{l}\text { Situational } \\
\text { Factors }\end{array}$ & $\begin{array}{r}\text { Social Factors } \begin{array}{c}\text { Cultural } \\
\text { Factors }\end{array}\end{array}$ \\
\hline$\overline{\text { CB17 }}$ & .830 & & & & \\
\hline CB14 & .817 & & & & \\
\hline CB15 & .814 & & & & \\
\hline CB16 & .763 & & & & \\
\hline CB18 & .760 & & & & \\
\hline CB19 & .747 & & & & \\
\hline CB11 & .678 & & & & \\
\hline CB21 & .674 & & & & \\
\hline CB22 & .673 & & & & \\
\hline CB13 & .649 & & & & \\
\hline$\overline{\mathrm{CB} 38}$ & 809 & & & & \\
\hline CB37 & .790 & & & & \\
\hline CB36 & .782 & & & & \\
\hline CB39 & .717 & & & & \\
\hline CB35 & .714 & & & & \\
\hline CB34 & 699 & & & & \\
\hline CB31 & .694 & & & & \\
\hline CB32 & .693 & & & & \\
\hline$\overline{\mathrm{CB} 7}$ & & .872 & & & \\
\hline CB8 & & .863 & & & \\
\hline CB6 & & .840 & & & \\
\hline CB5 & & .830 & & & \\
\hline CB4 & & .738 & & & \\
\hline CB1 & & .587 & & & \\
\hline$\overline{\mathrm{CB} 47}$ & & & .841 & & \\
\hline CB49 & & & .809 & & \\
\hline CB46 & & & .786 & & \\
\hline CB48 & & & .741 & & \\
\hline CB45 & & & .641 & & \\
\hline CB50 & & & .625 & & \\
\hline$\overline{\mathrm{CB} 27}$ & & & & .875 & \\
\hline CB29 & & & & .846 & \\
\hline CB26 & & & & .821 & \\
\hline CB28 & & & & .809 & \\
\hline CB30 & & & & .586 & \\
\hline$\overline{\mathrm{CB} 40}$ & & & & & $\begin{array}{l}.709 \\
\end{array}$ \\
\hline CB41 & & & & & .688 \\
\hline CB42 & & & & & .638 \\
\hline CB44 & & & & & .567 \\
\hline$\overline{\text { CB25 }}$ & & & & & .764 \\
\hline CB24 & & & & & .760 \\
\hline CB23 & & & & & .682 \\
\hline
\end{tabular}

Table 1: Rotated component matrix

Confirmatory Factor Analysis: In scale purification next stage after confirming factor structure is to purify the items using confirmatory factor analysis (CFA). According to Joreskog \& Sorbom (2004) confirmatory factor analysis is a distinct case of structural equational modelling (SEM), also known as covariance structure model (McDonald, 1978).

To calculate the CFA, 2nd pilot survey was conducted on a fresh sample of 400 Saudi Nationals for $2^{\text {nd }}$ pilot survey 850 questionnaires were distributed through convenience sampling method, out of 850 questionnaires only 410 questionnaires were returned. The responses were carefully checked for the missing information and incompleteness; 10 responses were dropped. Final data set comprised of 400 responses giving a response rate of $47 \%$. Out of 400 respondents $40 \%$ respondents were students and rest 
were employees from different sectors, similarly $38 \%$ of respondents were females and $62 \%$ were males. $65 \%$ of respondents were from urban areas and $35 \%$ were from rural areas. Nearly $67 \%$ of respondents were graduates and $23 \%$ were having higher qualifications.

Various eminent researchers argue that the perfection of psychometric properties of an instrument depends on the reiteration of CFA (Bagozzi, 1980) and Arnold, \& Reynolds, 2003). To test the stability of 35 items, 7 factor model CFA was conducted using AMOS 19.0. The initial indices of the model were $\mathrm{CMIN} / \mathrm{DF}=3.067$; RMR $=.084$; GFI $=.861$; $\mathrm{AGFI}=.870$; $\mathrm{CFI}=.898$; and RMSEA $=.072$. The results revealed that indices of the model were close to threshold values. An inspection of the modification indices ranging from 4.0 to 90.7 required deletion of 7 items. Researcher used the modification indices, factor loading, subjective judgment, and expert opinion before deleting the items. After a number of iterations, the indices of the final CFA model with remaining 35 items (refer to Table 2) produced a good fit. The indices of final model were $\mathrm{CMIN} / \mathrm{DF}=2.705 ; \mathrm{RMR}=.081 ; \mathrm{GFI}=.906$; AGFI = .911; CFI = .925; and RMSEA = .063 (Fig. 2).

\begin{tabular}{|c|c|}
\hline Items & \\
\hline Are you aware of online shopping (CB 7) & \\
\hline Do you know that you can shop world class brands from home (CB 8) & \\
\hline Do you know that you can shop from anywhere in the world from home (CB 6) & Attitude (ATT) \\
\hline Do you know online shopping prices are much less than traditional shopping (CB 5) & \\
\hline Easy Navigation in online websites makes it more convenient to shop (CB 14) & \\
\hline Shopping websites equipped with audio assistant makes shopping easy. (CB 15) & \\
\hline I feel delighted with color combination (attractiveness) of the website. (CB 16) & \\
\hline Video and 3D displays encourages online shopping. (CB 18) & Web \\
\hline Online shopping sites provides sufficient information of every product. (CB 19) & Atmosphere \\
\hline Clarity of the website influences my decision of purchase. (CB 11) & $(\mathrm{WA})$ \\
\hline Speed of the shopping website improves my search among varied collection of products. (CB 21) & \\
\hline I get motivated when my reference group prefers online shopping. (CB 40) & \\
\hline I get convinced when my friends do shopping from online sites. (CB 41) & Social Factors \\
\hline I feel encouraged when my family members shop from online sites. (CB 42) & $(\mathrm{SOCF})$ \\
\hline I feel online products are in-line with my taste and social status. (CB 44) & \\
\hline I feel online shopping is more convenient. (CB 27) & \\
\hline Online shopping has more variety of product available. (CB 29) & Situational \\
\hline I have sufficient knowledge of using internet shopping. (CB 26) & Factors (SITF) \\
\hline Online shopping is available $24 \times 7$. (CВ 28) & \\
\hline Do you think that individual's medical circumstances influence to shop online? (CB 30). & \\
\hline Online shopping provides a wide range of product selection. (CB 38) & \\
\hline Online shopping sites delivers the product on time. (CB 37) & \\
\hline Online shopping sites provide beneficial offers/promotions/discounts. (CB 36) & \\
\hline Loyalty programs of the e-retailer motivates for online shopping. (CB 39) & \\
\hline Good customer support/service motivates me for online shopping. (CB 35) & E-Retailer \\
\hline Flexible payments systems attract me to shop online. (CB 34) & Image (ERI) \\
\hline Shopping sites which preserves good return policy motivate me to shop online. (CB 31) & \\
\hline Product Quality is up-to the mark as shown on website. (CB 47) & \\
\hline Products purchased online are safely delivered. (CB 49) & \\
\hline Online shopping sites provide competitive price. (CB 46) & Trust (TRUST) \\
\hline I feel my personal information is kept confidential by online shopping sites. (CB 48) & \\
\hline My financial information is safe and secure with online shopping sites. (CB 45) & \\
\hline My cultural values influence my decision of buying online products. (CB 25) & Cultural Factors \\
\hline I feel my language hurdles my decisions of online shopping. (CB 24) & (CULF) \\
\hline Online shopping suits my customs and traditions. (CB 23) & \\
\hline
\end{tabular}

Table 2: Items retained in final scale 


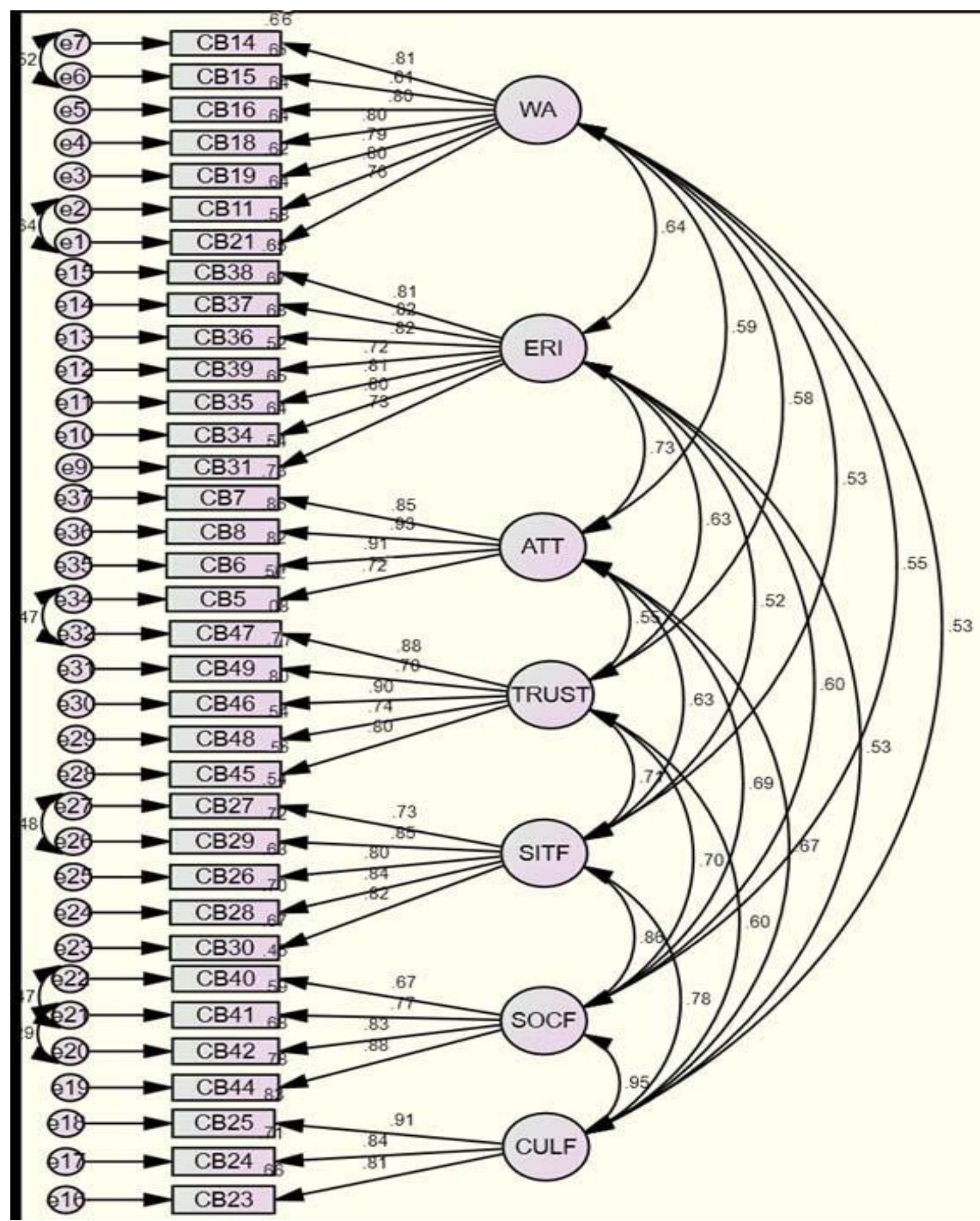

Fig. 2. Confirmatory Factor Analysis.

\section{Phase III: Scale evaluation}

Unidimensionality and reliability: The results confirmed the unidimensionality of the constructs, as each statement is related with one and only one fundamental construct (Gerbing \& Anderson 1988; and Bollen 1989). The value of composite reliability ranges from .86 to .92 Table 3 and value of Cronbach alpha ranges from .789 to .919 , reflecting the internal consistency and good construct reliability (Nunnally \& Bernstein 1994).

Construct and discriminant validity: As per suggestions of Hair et al. (1998) construct validity of an instrument can be established by measuring the average variance extracted of all factors of measurement model. All the factors measuring consumer behavior in present study possesses average variance extracted score greater than .50 which provides sufficient evidence of construct validity (Fornell \& Larcker 1981).

Fornell and Larcker (1981) and Bove et al. (2009) stated that the discriminant validity of a construct can be established by comparing maximum shared variances (MSV which is actually square of correlation between two constructs), with average variance extracted (AVE) of each construct. The values of MSV was 
found less than the AVE of different factors which gives evidence of good discriminant validity (Fornell \& Larcker 1981; and Bove et al. 2009).

\begin{tabular}{|c|c|c|c|}
\hline Domains & Factor Loading & Composite Reliability & Average Variance Extracted \\
\hline \multirow{7}{*}{ Web Atmosphere } & .81 & 0.92 & 0.63 \\
\hline & .81 & & \\
\hline & .80 & & \\
\hline & .80 & & \\
\hline & .79 & & \\
\hline & .80 & & \\
\hline & .76 & & \\
\hline \multirow{7}{*}{ E-Retailers Image } & .81 & 0.91 & 0.62 \\
\hline & .82 & & \\
\hline & .82 & & \\
\hline & .72 & & \\
\hline & .81 & & \\
\hline & .80 & & \\
\hline & .73 & & \\
\hline \multirow[t]{4}{*}{ Attitude } & .85 & 0.91 & 0.73 \\
\hline & .93 & & \\
\hline & .91 & & \\
\hline & .72 & & \\
\hline \multirow[t]{5}{*}{ Trust } & .88 & 0.90 & 0.65 \\
\hline & .70 & & \\
\hline & .90 & & \\
\hline & .74 & & \\
\hline & .80 & & \\
\hline \multirow[t]{5}{*}{ Situational Factors } & .73 & 0.90 & 0.65 \\
\hline & .85 & & \\
\hline & .80 & & \\
\hline & .84 & & \\
\hline & .82 & & \\
\hline \multirow[t]{4}{*}{ Social Factors } & .67 & 0.86 & 0.62 \\
\hline & .77 & & \\
\hline & .83 & & \\
\hline & .88 & & \\
\hline \multirow{3}{*}{ Cultural Factors } & .91 & 0.88 & 0.72 \\
\hline & .84 & & \\
\hline & .81 & & \\
\hline
\end{tabular}

Table 3: Factor loading, composite reliability and average variance extracted (AVE).

\section{Discussion}

The study has adopted renowned and highly valid scale development procedures by Churchill (1979) and Hinkin (1995). A 35-item scale covering seven factors was developed which measures online consumer behavior (See Annexure 1). The analysis of the data across different samples reveals high internal consistency. Further the factor loading, composite reliability and discriminant validity of the instrument highlight the validity and reliability. The study has highlighted that among all the seven factors 'Web atmosphere' has emerged out to be one of the most significant factors. The importance of web atmosphere has been highlighted in some prior studies also (Aljukhadar \& Senecal 2011) but this study is first of its kind in Saudi Arabian context. The study highlights that the second most important factor is the E-retailors image. Prior studies have also highlighted that is e-retailers image which covers company size and reputation can have considerable influence on the consumer behavior (Chen \& Barnes 2007; Constantinides, 2004; Dennis, Merrilees, Jayawardhena, \& Tiu Wright, 2009; Eurofood, 2000). The study highlights that the third factor which has a significant impact on the online consumer behavior is the consumer attitude. These findings are consistent with the findings of other studies (Bhattacherjee, 
2000; Bianchi \& Andrews 2012; Chan, Cheung, Kwong, Limayem, \& Zhu, 2003). The findings from this study has also highlighted that trust which includes disposition to trust, institution-based trust, trusting beliefs, and trusting intentions can have a significant influence on the online consumer behavior. Previous researchers have also highlighted the influence of trust on consumer behavior (McKnight, Choudhury, \& Kacmar, 2002; Bianchi \& Andrews 2012). The other factors highlighted include situational factors, social factors and cultural factors. Some of the previous studies have also highlighted the importance of these factors (Bianchi \& Andrews 2012; Darley, et al., 2010) but not in the context of online consumer bhevaiour and in Saudi Arabian Context.

\section{Managerial Implications}

This study has implications both for academia and as well as the practitioners. The main contribution lies in bridging the gap between online and offline consumer buying behavior. The study contributes to the consumer behavior literature by developing a valid and reliable scale to measure online consumer behavior. The study measures online consumer behavior across various touch points. Findings of this study have several implications for the marketers of online marketplace platforms.

First, the study has highlighted that web atmosphere is one of the most import factors in online buying. Marketing managers need to design websites which are interactive and also take care of diverse needs of customers like payment, product specifications, reviews from previous customers and after sales services. The atmosphere in the website should be conducive and interactive enough for the customer because unlike offline shopping online shopping lacks that personal touch. Second, the scale developed in this study would be helpful in measuring E-retailors image. Marketers can take the help of this scale to judge the present and past perception of customers by taking pre and post responses from the customers.

Third, the study can help marketers to access the level of trust which consumers have in Ecommerce businesses. This will help them to analyze and access the discrepancies, thereby by channelizing the feedback they will be able to rectify the situation. Fourth, the scale will help marketers to maintain a positive image of their businesses in the eyes of its customers. Fifth, the study has also revealed that situational factors, social factors and even cultural factors do have an influence on the online consumer behavior.

\section{Limitation and scope for future research}

The scope of the study is restricted to Riyadh, the capital city of Saudi Arabia. Therefore, researcher doesn't claim generalization of the results. Further research should be conducted from other markets in Middle East to access the differences in the consumer behavior. Researchers can also conduct a future study in emerging and developed markets to aces the differences in consumer behavior.

Second, the various statistical tools used in this study are sample size specific, which means that results tend to fluctuate if a bigger sample is taken. Therefore, future research can be conducted involving a bigger sample to access the difference in the results, if any. Third, future researchers can also study other variables like consumer intention to purchase and the overall decision cycle of the purchase with special focus on the E-commerce.

Annexure I

Online Consumer Behavior

\begin{tabular}{|l|l|l|l|l|l|l|}
\hline S & Statement & SA & A & N & D & SD \\
\hline & Are you aware of online shopping & & & & & \\
\hline & Do you know that you can shop world class brands from home & & & & & \\
\hline & Do you know that you can shop from anywhere in the world from home & & & & & \\
\hline Do you know online shopping prices are much less than traditional shopping & & & & & \\
\hline & Easy Navigation in online websites makes it more convenient to shop & & & & & \\
\hline & Shopping websites equipped with audio assistant makes shopping easy. & & & & & \\
\hline I feel delighted with color combination (attractiveness) of the website & & & & & \\
\hline & Video and 3D displays encourages online shopping & & & & \\
\hline & Online shopping sites provides sufficient information of every product & & & & \\
\hline & Clarity of the website influences my decision of purchase & & & & \\
\hline
\end{tabular}

www.jbrmr.com A Journal of the Academy of Business and Retail Management (ABRM) 


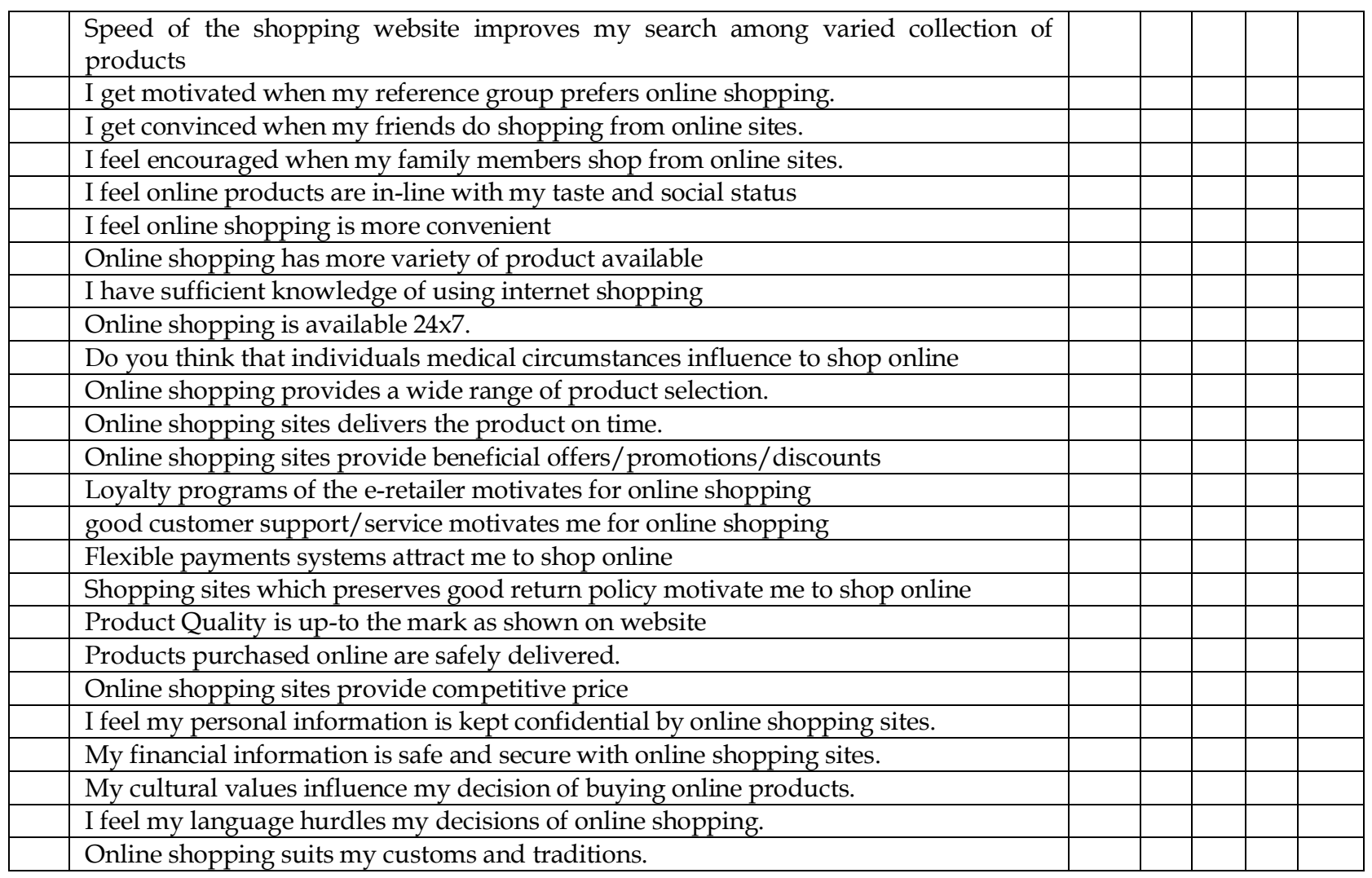

\section{References}

Aljukhadar, M., \& Senecal, S. (2011). Segmenting the online consumer market. Marketing intelligence \& planning, 29(4), 421-435.

Al-Maghrabi, T., Dennis, C., \& Vaux Halliday, S. (2011). Antecedents of continuance intentions towards e-shopping: the case of Saudi Arabia. Journal of Enterprise Information Management, 24(1), 85-111.

Anderson, J. C. \& Gerbing, D. W. (1982). Some methods for respecifying measurement models to obtain unidimensional construct measurement. Journal of Marketing Research, 19(4), 453-461.

Arnold, M. J. \& Reynolds, K. E. (2003). Hedonic shopping motivations. Journal of Retailing,79(2) 77-95.

Bagozzi, R. P. (1980). Causal Models in Marketing, Wiley, New York, NY.

Bagozzi, R. P., Youjae, Y. \& Lyne, W. P. (1991). Assessing construct validity in organizational research. Administrative Science Quarterly, 36(3), 421-458.

Barber, W. \& Badrew A. (1998) Culturability. The merging of culture and usability. Proceedings of the 4th conference on human factors and the web. www.research.att.co/conf/hfweb/proceedings/barder/index.htm1998.

Barnes, S. J., Bauer, H. H., Neumann, M. M., \& Huber, F. (2007). Segmenting cyberspace: a customer typology for the internet. European journal of marketing, 41(1/2), 71-93.

Bettman, J. R. (1979). Memory factors in consumer choice: A review. The Journal of marketing, 37-53.

Bhat, S. A. \& Bashir, M. (2017). Measuring ICT orientation: Scale development \& validation. Education and Information Technologies. doi: 10.1007/s10639-017-9656-4

Bhattacherjee, A. (2000). Acceptance of e-commerce services: the case of electronic brokerages. IEEE Transactions on systems, man, and cybernetics-Part A: Systems and humans, 30(4), 411-420.

Bhattacherjee, A. (2001). Understanding information systems continuance: an expectation-confirmation model. MIS Quarterly, 25(3), 351-70.

Bianchi, C., \& Andrews, L. (2012). Risk, trust, and consumer online purchasing behaviour: a Chilean perspective. International Marketing Review, 29(3), 253-275.

Bollen, K. A. (1989). Structural equations with latent variables. New York: Wiley.

Boulding, K.E. (1956), The Image, University of Michigan, Ann Arbor, MI. 
Bove, L. L., Pervan, S. J., Beatty, S. E., \& Shiu, E. (2009). Service worker role in encouraging customer organizational citizenship behaviors. Journal of Business Research, 62(7), 698-705.

Chan, G., Cheung, C., Kwong, T., Limayem, M., \& Zhu, L. (2003). Online consumer behavior: a review and agenda for future research. BLED 2003 Proceedings, 43.

Chau, P., Cole, M., Massey, A, P., \& O'Keefe, R, M. (2002). Cultural differences in consumer's on-line behaviors. Commun ACM, 45(10), 38-143.

Chen, Y. H., \& Barnes, S. (2007). Initial trust and online buyer behaviour. Industrial management $\mathcal{E}$ data systems, 107(1), 21-36.

Cheung, C. M., \& Lee, M. K. (2001). Trust in internet shopping: instrumental development and validation through classical and modern approaches. Journal of Global Information Management, 9(3), 25-41.

Cheung, C. M., Chan, G. W., \& Limayem, M. (2005). A critical review of online consumer behavior: Empirical research. Journal of electronic commerce in organizations, 3(4), 1.

Childers, T. L., Carr, C. L., Peck, J., \& Carson, S. (2001). Hedonic and utilitarian motivations for online retail shopping behavior. Journal of retailing, 77(4), 511-535.

Cho, J. (2006). The mechanism of trust and distrust formation and their relational outcomes. Journal of retailing, 82(1), 25-35.

Churchill, G. A. Jr (1979). A paradigm for developing better measures of marketing constructs. Journal of Marketing Research, 16(1), 64-73.

Constantinides, E. (2004). Influencing the online consumer's behavior: The Web experience. Internet research, 14(2), 111-126.

Costello, A. B. \& Osborne, J. W. (2005). Best practices in exploratory factor analysis: four recommendations for getting the most from your analysis. Practical Assessment, Research and Evaluation,10(7), 1-9

Crego, E.T. Jr \& Schiffrin, P.D. (1995), Customer-centered Reengineering: Remapping for Total Customer Value, Irwin, Burr Ridge, IL.

Darley, W. K., Blankson, C., \& Luethge, D. J. (2010). Toward an integrated framework for online consumer behavior and decision-making process: A review. Psychology \& marketing, 27(2), 94-116.

Das, S., Echambadi, R., McCardle, M., \& Luckett, M. (2003). The effect of interpersonal trust needs for cognition, and social loneliness on shopping, information seeking and surfing on the web. Marketing Letters, 14(3), $185-202$.

Dash, S., \& Saji, K. B. (2008). The role of consumer self-efficacy and website social-presence in customers' adoption of B2C online shopping: an empirical study in the Indian context. Journal of international consumer marketing, 20(2), 33-48.

Davis, L., Wang, S., \& Lindridge, A. (2008). Culture influences on emotional responses to on-line store atmospheric cues. Journal of Business Research, 61(8), 806-812.

Demangeot, C., \& Broderick, A. J. (2007). Conceptualising consumer behaviour in online shopping environments. International Journal of Retail \& Distribution Management, 35(11), 878-894.

Dennis, C., Merrilees, B., Jayawardhena, C., \& Tiu Wright, L. (2009). E-consumer behaviour. European journal of Marketing, 43(9/10), 1121-1139.

Engel, J. F., Blackwell, R. D. \& Miniard, P. W. (2001). Consumer Behavior, The Dryden Press Series in Marketing.

Evanschitzky, H., Iyer, G. R., Hesse, J. \& Ahlert, D. (2004). E-satisfaction: a re-examination. Journal of Retailing, 80(3), 239-47.

Falk, T., Schepers, J., Hammerschmidt, M., \& Bauer, H. H. (2007). Identifying cross-channel dissynergies for multichannel service providers. Journal of Service Research, 10(2), 143-160.

Fishbein, M., \& Ajzen, I. (1975). Belief, attitude, intention and behavior: An introduction to theory and research.

Folkes, V. S. (1988). Recent attribution research in consumer behavior: A review and new directions. Journal of consumer research, 14(4), 548-565.

Fornell, C., \& Larcker, D. F. (1981). Evaluating structural equation models with unobservable variables and measurement error. Journal of Marketing Research, 18(1), 39-50.

Fung, R., \& Lee, M. (1999). EC-trust (trust in electronic commerce): exploring the antecedent factors. AMCIS 1999 Proceedings, 179.

Garg, R., Rahman, Z., \& Qureshi, M. N. (2014). Measuring customer experience in banks: scale development and validation. Journal of Modelling in Management, 9(1), 87-117.

Gerbing, D. W., \& Anderson, J. C. (1988). An updated paradigm for scale development incorporating unidimensionality and its assessment. Journal of Marketing Research, 25, 186-192.

Goldsmith, R. E. \& Bridges, E. (2000). E-Tailing VS Retailing: Using Attitudes to Predict Online Buying Behavior. Quarterly Journal of Electronic Commerce, 1(3), 245-253. 
Hair, J. F., Anderson, R. E., Tatham, R. L. \& Black, W. C. (1998). Multivariate Data Analysis, 5th ed., Prentice-Hall, Englewood Cliffs, NJ.

Hair, J. F., Black, W. C., Babin, B. J., \& Anderson, R. E. (2010). Multivariate data analysis - A global perspective (7th ed.). Upper Saddle River: Pearson Prentice Hall.

Hansen, T. (2008). Consumer values, the theory of planned behaviour and online grocery shopping. International Journal of Consumer Studies, 32(2), 128-137.

Hinkin, T. R. (1995). A brief tutorial on the development of measures for use in survey questionnaires. Organizational Research Methods, 1(1), 104-121.

Hofstede, F. T., Steenkamp, J. B. E., \& Wedel, M. (1999). International market segmentation based on consumerproduct relations. Journal of Marketing Research, 1-17.

Jarvenpaa, S. L., Tractinsky, N., \& Vitale, M. (2000). Consumer trust in an Internet store. Information technology and management, 1(1-2), 45-71.

Jiang, P., Jones, D. B., \& Javie, S. (2008). How third-party certification programs relate to consumer trust in online transactions: An exploratory study. Psychology \& Marketing, 25(9), 839-858.

Joreskog, K. G. \& Sorbom, D. (2004). LISREL 8.7, Scientific Software International Inc., Chicago, IL.

Kang, H., Hahn, M., Fortin, D. R., Hyun, Y. J., \& Eom, Y. (2006). Effects of perceived behavioral control on the consumer usage intention of e-coupons. Psychology E Marketing, 23(10), 841-864.

Karatepe, O. M., Yavas, U. \& Babakus, E. (2005). Measuring service quality of banks: scale development and validation. Journal of Retailing and Consumer Services, 12(5), 373-383.

Karatepe, O. M., Yavas, U. \& Babakus, E. (2005). Measuring service quality of banks: scale development and validation. Journal of Retailing and Consumer Services, 12(5), 373-383.

Keen, C., Ruyter, K. D., Wetzels, M., \& Feinberg, R. (2000). An empirical analysis of consumer preferences regarding alternative service delivery modes in emerging electronic service markets. Quarterly Journal of Electronic Commerce, 1(1), 31-47.

Khan, M. M., Asad, H. \& Mehboob, I. (2017). Investigating the consumer behavior for halal endorsed products: Case of an emerging Muslim market. Journal of Islamic Marketing, 8(4), 625-641.

Kim, J. H., Kim, M. \& Kandampully, J. (2009). Buying environment characteristics in the context of e-service. European Journal of Marketing, 43(9/10), 1188-204.

Kim, J., Yang, K. \& Yong Kim, B. (2013). Online retailer reputation and consumer response: examining cross cultural differences. International Journal of Retail \& Distribution Management, 41(9), 688-705.

Kim, M. \& Lennon, S. (2008). The effects of visual and verbal information on attitudes and purchase intentions in Internet shopping. Psychology E Marketing, 25, 146-178.

Koernig, S. K. (2003). E-scapes: The electronic physical environment and service tangibility. Psychology E Marketing, 20(2), 151-167.

Korgaonkar, P., Silverblatt, R. \& Girard, T. (2006). Online retailing, product classifications, and consumer preferences. Internet Research, 16(3), 267-288.

Lawshe, C. H. (1975). A quantitative approach to content validity. Personnel psychology, 28(4), 563-575.

Lee, J., Kim, J., \& Moon, J. Y. (2000, April). What makes Internet users visit cyber stores again? Key design factors for customer loyalty. In Proceedings of the SIGCHI conference on Human Factors in Computing Systems (pp. 305-312). ACM.

Lee, M. K., \& Turban, E. (2001). A trust model for consumer internet shopping. International Journal of electronic commerce, 6(1), 75-91.

Liang, T. P., \& Lai, H. J. (2002). Effect of store design on consumer purchases: an empirical study of on-line bookstores. Information \& Management, 39(6), 431-444.

Lim, H., \& Dubinsky, A. J. (2005). The theory of planned behavior in e-commerce: Making a case for interdependencies between salient beliefs. Psychology \& Marketing, 22(10), 833-855.

Mazaheri, E., Richard, M. -O., \& Laroche, M. (2011). Online consumer behavior: Comparing North American and Chinese website visitors. Journal of Business Research, 64(9), 958-965.

McDonald, R. P. (1978). A simple comprehensive model for the analysis of covariance structures. British Journal of Mathematical and Statistical Psychology, 31(1), 59-72.

McKnight, D. H., Choudhury, V. \& Kacmar, C. (2002). Developing and validating trust measures for e-commerce: An integrative typology. Information systems research, 13(3), 334-359.

Menon, S., \& Kahn, B. (2002). Cross-category effects of induced arousal and pleasure on the Internet shopping experience. Journal of retailing, 78(1), 31-40.

Nunnally, J. C. \& Bernstein, I. H. (1994). Psychometric Theory, 3rd ed., McGraw-Hill, New York, NY.

Nunnally, J. C. (1978). Psychometric theory. New York: McGraw-Hill. 
Nunnally, J. C., \& Bernstein, I. H. (1994). Psychometric theory (3rd ed.). New York: McGraw-Hill.

Parsons, A.G. (2002). Non-functional motives for online shoppers: why we click. Journal of Consumer Marketing, 19(5), 380-92.

Parsuraman, A., Zeithaml, V. A. \& Berry, L. L. (1988). A multiple-item scale for measuring consumer perceptions of service quality. Journal of Retailing, 64(1), 12-40.

Petrissans, A. (1999), "Customer relationship management: the changing economics of customer

relationship", white paper, IDC and Gap Gemini.

Richard, M. O., \& Habibi, M. R. (2016). Advanced modeling of online consumer behavior: The moderating roles of hedonism and culture. Journal of Business Research, 69(3), 1103-1119.

Rohm, A. J. \& Swaminathan, V. (2004). A typology of online shoppers based on shopping motivations. Journal of Business Research, 57(7), 748-57.

Schiffman, L. G., Sherman, E., \& Long, M. M. (2003). Toward a better understanding of the interplay of personal values and the Internet. Psychology E Marketing, 20(2), 169-186.

Schoenbachler, D. D., \& Gordon, G. L. (2002). Multi-channel shopping: understanding what drives channel choice. Journal of Consumer Marketing, 19(1), 42-53.

Shavitt, S., \& Cho, H. (2016). Culture and consumer behavior: the role of horizontal and vertical cultural factors. Current opinion in psychology, 8, 149-154.

Shim, S., Eastlick, M. A., Lotz, S. L., \& Warrington, P. (2001). An online prepurchase intentions model: The role of intention to search. Journal of retailing, 77(3), 397-416.

Skinner, B. F. (1990). The behavior of organisms: An experimental analysis. BF Skinner Foundation.

Song, J., \& Zahedi, F. M. (2005). A theoretical approach to web design in e-commerce: a belief reinforcement model. Management Science, 51(8), 1219-1235.

Sorce, P., Perotti, V., \& Widrick, S. (2005). Attitude and age differences in online buying. International Journal of Retail $\mathcal{E}$ Distribution Management, 33(2), 122-132.

Szymanski, D. M. \& Hise, R. T. (2000). e-Satisfaction: an initial examination. Journal of Retailing, 76(3), 309-22.

Tabachnick, B. G. \& Fidell, L. S. (1996). Using Multivariate Statistics, 3rd ed., HarperCollins College, New York, NY.

Talal Al-maghrabi, Charles D. \& Sue V. H. (2011). Antecedents of continuance intentions towards e-shopping: the case of Saudi Arabia. Journal of Enterprise Information Management, 24(1), pp.85-111. 